\title{
ESSAY
}

\section{COMPENSATION AND COMMENSURABILITY}

\author{
MARGARET JANE RADIN $\dagger$
}

\section{INTRODUCTION}

When someone who has lost an arm in an accident receives $\$ 100,000$ in compensation through the tort system, what does this transaction mean? Does it mean that an arm is "worth" $\$ 100,000$ ? In this Essay I want to explore the disputed "equation" between bodily integrity and money. I am writing about meaning-the way human interactions are understood by a community sharing a concept in practice. The concept in practice I focus on is compensation, in particular compensation for personal injury. Of course, compensation remedies are pervasive in law, so the investigation I offer here is just a first look at a piece of the picture.

I will suggest that our legal practice reflects conflict in how compensation for personal injury is understood-that compensation is a contested concept. A commodified conception of compensation, in which harm to persons can be equated with a dollar value, coexists with a noncommodified conception, in which harm cannot be equated with dollars. In the commodified conception, harm and dollars are commensurable, and in the noncommodified conception, they are incommensurable. After describing the significance of commensurability as a philosophical issue, I will go on to suggest that once we understand the relationship of commensurability to the issue of what compensation means, we will be in a better position to understand the contemporary debate about whether the tort system should compensate for "nonpecuniary" harms.

$\dagger$ Copyright (c) 1993, Margaret Jane Radin.

Professor of Law, Stanford University. An earlier version of this Essay was delivered as the 1993 Brainerd Currie Lecture at the Duke University School of Law on March 29, 1993. I am grateful to the Duke law faculty for inviting me and for their comments and questions. Thanks also to Thomas C. Grey, Mark Kelman, Cass Sunstein, and Catharine P. Wells for helpful comments on an earlier draft. 
Moreover, understanding the relevance of commensurability to this debate about compensation should shed light on the general problem of how to conceive of corrective justice. If we do not accept a commodified conception of compensation, in which harms and money are commensurable, then payment of money cannot restore persons to the status quo ante, and corrective justice will be impossible if that is what we demand of it. In this Essay I draw attention to an alternative conception of corrective justice. In this alternative conception, compensation is understood not as a commensurable quid pro quo for harm, but rather as a form of redress: affirming public respect for the existence of rights and public recognition of the transgressor's fault with regard to disrespecting rights.

To begin, I distinguish between "commodified" and "noncommodified" conceptions of compensation, and explain how these different understandings of compensation relate to different views of the purpose of tort recovery: deterrence and corrective justice.

\section{TWo KINDS OF VIEWS ABOUT COMPENSATION}

\section{A. Commodified Conceptions}

By market rhetoric, which I sometimes call the discourse of commodification, I mean conceiving of everything people value as if it were a commodity subject to market exchange. (When Judge Richard Posner says that children are the "household commodity that places the greatest demands on the wife's time,"1 he is using market rhetoric.) The proponents of law and economics conceive of tort law in market rhetoric. Tort law is an engine for accomplishing economic efficiency by maximizing the amount of dollar value in the world, given some set of entitlements as a starting point. A deterrence rationale most comfortably inhabits this market model. It tells us to perform a cost-benefit analysis: We should pay out damages as long as the cost to society of paying them will deter possible tortfeasors from imposing greater accident costs in the future.

1. RICHARD A. POSNER, ECONOMIC ANALYSIS OF LAW 141 (4th ed. 1992); see also GARY BECKER, A TREATISE ON THE FAMILY (1981) (using market rhetoric and methodology to analyze marriage, births, divorce, division of labor in households, prestige, sex, love, and all aspects of family structure and experience). 
In a pure deterrence model, can we even conceive of damages as "compensatory?" Perhaps not. If there is a core understanding in which "compensatory" denotes some direct relationship between the damages paid and the victim's loss and its magnitude, then, at least prima facie, damages are not "compensatory" in the pure deterrence model. Someone might object that I ought not to begin an essay on compensation with a conceptual regime whose "compensatory" character can be questioned. Yet the deterrence model, at least when couched in market rhetoric, does equate the dollar value of damages with the dollar value of harm. This is the equation I want to explore, and I think I can usefully let the question whether deterrence-based damages are compensatory hang fire while I try to explain the way that compensation is a contested concept.

In the deterrence model, the equation comes about as follows. An economically rational tortfeasor would choose to implement safety measures that would prevent an accident if these measures cost it less than paying damages, and would choose to let an accident happen if the safety measures to prevent it would cost more than paying the damages. Society controls the level of safety measures, and thus the amount of harm from accidents, by the level at which it sets damages. The optimal level of safety measures for society, according to the model, is the level at which any further expenditures for safety would be more expensive than the "costs" of the harms that will occur without them. Thus, in this model, the harm to victims must be a known dollar value in order to set the proper amount of damages. Even if the reason the tortfeasor must pay is to achieve deterrence rather than to "compensate" the victim for her loss, in this model there is an equation between the value of harm and the value of damages. ${ }^{2}$

This view of damages conceives of harm to victims in market rhetoric. Injuries to life and health are "costs," just as the dollars expended for safety measures, against which they are balanced,

2. In a pure deterrence model, it is a further question whether the damages should be paid to the victim. In favor of doing so one can postulate "demoralization" costs that would otherwise accrue, but against doing so one can postulate that more efficient uses can be found for the money. See Guido CalabresI, THE Costs of Accidents: A Legal aNd ECONOMic analysis 88-94 (1970); Peter Cane, TORT Law and ECONOMIC INTERESTS 492-93 (1991); A. MITCHELl Polinsky \& YeON-KoO CHE, DeCoupling Liability: OPTIMAL INCENTIVES for CARE AND LITIGation (National Bureau of Economic Research Working Paper No. 3634, 1991). 
are "costs." I call this a commodified conception because it conceives of the harm to the injured victim as commensurable with money, as if the victim's interest in being free of injury were the same as money or a fungible commodity she possessed. ${ }^{3}$

In this commodified conception, theoretically the harm is simply a cost to the victim. In market rhetoric, if I lose my arm or my car keys, either way it is simply a cost, although one cost may be greater than the other. To those of us who do not conceive of everything in terms of the market, market rhetoric is a form of reductionism. It "reduces" to the language of market value something that is appropriately conceptualized in some other language of value.

Many who are sympathetic to economic reasoning do not adopt this pure deterrence model. Instead, at least implicitly, they adopt a mixed view in which deterrence is consequentially important because it creates incentives for efficient activities and uses of resources, but rights like bodily integrity also are recognized. In the mixed view, rights are set by natural law, or by a rule-utilitarian precommitment procedure, or are simply presupposed, but in any event are set by other than the same consequentialist concerns that animate deterrence.

Those who accept this kind of mixed economic view need not be troubled by the question I left hanging. Even if we think a core requirement of compensation is that payment bear a direct relationship to the individual victim's harm (so that in a pure deterrence model damages are not compensatory), the mixed economic view leaves room for a quid pro quo conception of compensation that squarely meets the requirement. In a quid pro quo conception of compensation, payment is in return for rights that are violated. Compensation restores the dollar equivalent of wrongfully divested entitlements to their rightful holders. Compensation makes the victim completely whole; that is its theoretical aim, at least. In market rhetoric, the victim is conceived to be indifferent between being harmed and getting the payment, and not being harmed at all. When the cost in dollars of the injury is paid, the victim is made whole.

The clearest form of a commodified conception of compensation appears in this mixed view, because the model treats injury

3. I will say more about commensurability below in Part II. 
and payment of damages exactly like the sale of a commodity the victim owns. I will refer to this as the core commodified conception. In a "transaction" between the injurer and the victim, the victim "trades" her bodily integrity for a suitable payment of money. In the economic pure deterrence model, the person's interest in bodily integrity is valued in dollars, as if it were a commodity the person owned; in the mixed view, in addition, the reason the tortfeasor must pay is to provide an equivalent in dollars to "compensate" for the divested commodity.

\section{B. Noncommodified Conceptions}

There is no canonical conception of corrective justice. In a rough understanding that $I$ find useful, corrective justice means to make required changes in an unjustified state of affairs between an injurer and a victim, when the injurer's activity has caused the injustice, so that such changes bring about a just state of affairs between them, and one that is related in a morally appropriate way to the status quo ante. A shorthand way of saying this is that corrective justice restores moral balance between the parties. From this perspective, tort law is an engine for bringing about corrective justice by requiring tortfeasors to make recompense to their victims. This view of tort law is not couched in market rhetoric. Its core concepts are rights and wrongs, not dollars and exchange.

Sometimes it appears that corrective justice can be accomplished by simply unwinding a wrongful interaction, restoring the parties to the status quo ante. Stolen money can be given back; goods obtained by fraud can be returned to the owner. Lawyers call this restitution. Some philosophers refer to rectification rather than restitution, and hold that rectification is what corrective justice requires. ${ }^{4}$ Rectification means restoring the status quo ante or a state of affairs equivalent in moral value to the status quo ante. Thus, even when restitution of money or goods can be made, it may not amount to rectification. Rectification may be incomplete without attention to other injuries brought about by the wrong, such as loss of use value, loss of opportunity to sell at a profit, or emotional distress.

4. See loren E. Lomasky, Persons, Rights, and the Moral COMmUNITY 142-44 (1987). 
In most personal injury cases, rectification in the form of restitution is not possible, and compensation is used instead. Here the question arises whether compensation and rectification may be treated as equivalent. Can compensation serve as rectification? For the core commodified conception of compensation, the answer is yes. In that conception, the victim is by definition indifferent between having been injured and having the money, on the one hand, and not having been injured but not having the money, on the other. The state of affairs after injury and compensation (having been injured and having the money) is identical with, or at least the moral equivalent of, the status quo ante (not having been injured but not having the money). But in other conceptions of compensation the answer is less clear that compensation can be rectification, or indeed clear that it cannot.

A noncommodified conception of compensation most comfortably inhabits a noncommodified view of torts in general, a view in which the central concepts are right and wrong, not "costs." In such a view, compensation does not imply commensurability between the harm and the payment; injuries and dollars are not ranked on a single scale of value. What else can compensation mean?

I want to call to mind the following possibility, which I think is the core noncommodified conception of compensation. Requiring payment is a way both to bring the wrongdoer to recognize that she has done wrong and to make redress to the victim. Redress is not restitution or rectification. Redress instead means showing the victim that her rights are taken seriously. It is accomplished by affirming that some action is required to symbolize public respect for the existence of certain rights and public recognition of the transgressor's fault in disrespecting those rights. In this conception of compensation, neither the harm to the victim nor the victim's right not to be harmed are commensurate with money. They are not conceptually equated with fungible commodities.

Many social democrats view the tort system not as an engine for delivering corrective justice, but rather as one aspect of a social insurance regime. ${ }^{5} \mathrm{~A}$ different noncommodified conception of compensation can be part of such a view. In a social insurance

5. See, e.g., STEPhen D. Sugarman, Dong Away WITH Personal InJuRy Law: NEW COMPENSATION MECHANISMS FOR VICTIMS, CONSUMERS, AND Business (1989). 
regime, society makes payments to those in need for various reasons, including social disadvantage regardless of cause, and emotional, mental, or physical disabilities, whether congenital or caused by illness ${ }^{*}$ or accident. ${ }^{6}$ In such a scheme, payments to accident victims are not compensatory in the two core senses I have described. They are not paid out to make the victim whole (core commodified conception) or to give the victim redress against someone whose activities have wronged her (core noncommodified conception). Payments may be compensatory in another sense, however, in that they are supposed to give the victim some needed wherewithal to lead a satisfactory life, thereby making up for-compensating for-the capabilities or advantages the victim lacks. This is a noncommodified conception because it does not suggest that the money payment is taken in trade for the harm, or equivalent to the harm in exchange value.

To summarize: Compensation seems to be a contested concept. There is a core commodified conception, in which payment for an injury is like buying a commodity, and a less central commodified conception, in which harms are "costs" to be measured against the costs of avoiding them. There is also a core noncommodified conception, in which payment provides redress but not restitution or rectification, and a less central noncommodified conception, in which payment makes up for certain social disadvantages. In Part III, I will explore how these different conceptions are implicated in the debate about compensation for pain and suffering. First, I turn to the notion of incommensurability.

\section{INCOMMENSURABILITY AND THE ISSUE OF COMPENSATION}

\section{A. Contra Utilitarianism}

Philosophers have puzzled over a problem named "incommensurability" in various contexts. In each of them, the problem is whether incommensurability exists. Although it goes by the same name, I am not sure to what extent incommensurability is usefully regarded as the same problem in all contexts. One context is a debate over relativism. ${ }^{7}$ If a commitment to the existence of

6. One leading example is New Zealand's comprehensive social insurance scheme. See Accident Compensation Act, No. 181 (1982) (N.Z.); GEOFFrEY W.R. PALMER, COMPENSATION FOR INCAPACITY: A STUDY OF LAW AND SOCIAL CHANGE IN NEW ZEALAND AND AUSTRALIA (1979).

7. For the parameters of this debate, see, for example, the essays collected in REL- 
incommensurability signifies a commitment to radical untranslatability between different cultural groups or different historical periods, then this commitment may support relativism. If the language, conventions, and forms of life of one group cannot be made at all intelligible in terms of the language, conventions, and forms of life of another, then it is thought that there is nothing to be said about which practices are better: they are incommensurable.

Another context, which appears to be subsumed by the broader debate about relativism, is a debate about Kuhnian paradigms in the philosophy of science. Kuhn argued that successive paradigms are incommensurable, inhabiting different world views, such that statements in one cannot be translated into statements in the other. ${ }^{8} \mathrm{He}$ thought it "illusive in principle" to suppose that successive paradigms are coming cioser and closer to some fixed reality existing independent of any paradigm. ${ }^{9}$ When his critics taxed him with relativism, he denied it by saying that paradigms could be judged better or worse by their success at puzzle-solving; he argned that it was characteristic of later paradigms to be better at puzzle-solving. ${ }^{10}$

Donald Davidson argued forcefully against the possibility of incommensurability, understood as radical untranslatability between cultural groups or historical periods. ${ }^{11}$ Hilary Putnam did the same for the Kuhnian subcategory. ${ }^{12}$ I cannot do justice here to these elegant and complex arguments, but their core is simple: The notion that we would be able to know such incommensurability when we saw it, much less proceed to talk about it, is conceptually incoherent. ${ }^{13}$ If we cannot make intelligible anything

ATIVISM: INTERPRETATION AND CONFRONTATION (Michael Krausz ed., 1989) and RELATIVISM: COGNITIVE AND MORAL (Michael Krausz \& Jack W. Meiland eds., 1982).

8. Thomas S. KuHN, THE StRUCTURE OF SCIENIIFIC REVOLUTIONS 148-50 (2d rev. ed. 1970).

9. Id. at 206.

10. Id. In my view, Kuhn's rejoinder just pushes the question back a stage. For some time our paradigms have been subsumed by a larger one in which puzzle-solving is what science is for, but what if some other group has an entirely different view of the point of science?

11. See Donald Davidson, On the Very Idea of a Conceptual Scheme, in INQUIRIES INTO TRUTH AND INTERPRETATION 183 (1984).

12. See Hillary PUtnam, Reason, Truth AND History 113-26 (1981).

13. Because of these arguments, radical untranslatability is not a promising definition of incommensurability. But untranslatability may be a matter of degree, and a milder understanding of untranslatability may shed more light on incommensurability; and may 
that some other group of human beings does, we would have no basis for identifying them as human beings in the first place.

Another context in which an argument about incommensurability comes up is debates in ethics about whether values can be summed. This is the kind of incommensurability $I$ think relevant to the questions I am exploring here. ${ }^{14}$ This notion of incommensurability is a broad strategy for attacking utilitarianism. ${ }^{15}$

It appears that a utilitarian injunction to maximize the sum of values implies either a reductionist or a scalar claim, or both. The reductionist claim is that there is one "stuff" of value to which all other values can be reduced, and this "stuff" is what we sum when we maximize. The scalar claim is that all values and packages of values can be arrayed in order from least valuable to most valuable on a continuous curve, so that we can maximize value by picking the highest package on the curve.

In arguments about ethics, the notion of incommensurability is meant to deny one or both of these claims. If incommensurability is put forward to deny the reductionist claim, then the claim that values are incommensurable means that there is no "stuff" that we can substitute equivalent amounts of when we try to sum values. If incommensurability is put forward to deny the scalar claim, then

make relativism attractive for some.

14. There is as yet little writing on inconmensurability by legal scholars, because we have just begun to notice that the debates in the philosophical literature might be important for law. See Richard H. Pildes \& Elizabeth S. Anderson, Slinging Arrows at Democracy: Social Choice Theory, Value Pluralism, and Democratic Politics, 90 ColUM. L. REv. 2121, 2145-66 (1990); Cass R. Sunstein, Incommensurability and Valuation in Law, 92 MiCH. L. REV. (forthcoming 1994); Richard Warner, Incommensurability as a Jurisprudential Puzzle, 68 CHI.-KENT L. REv. 147 (1992).

15. Martha Nussbaum makes clear that the inconmensurability debate in ethics is much older than controversies over utilitarianism. According to Nussbaum, Plato argued for "an ethical 'science of measurement,' at the heart of which is the belief in commensurability." MarTHA NUSSBAUM, Plato on Commensurability and Desire, in LOVE'S KNOWLEDGE 106 (1992).

One of Nussbaum's purposes in retrieving this Platonic argument is to comment on the present:

To pursue Plato's arguments . . will remind us that certain proposals in ethics and especially in economic theory that present themselves as innocuous extensions of ordinary belief and practice could actually lead, followed and lived with severity and rigor, to the end of human life as we currently know it. Id. at 107.

I have pursued a kindred path in worrying about the effect on human flourishing of conceiving of everything that people value in market rhetoric. See Margaret Jane Radin, Market-Inalienability, 100 HARV. L. REv. 1849, 1877-87 (1987). 
the claim that values are incommensurable means that there is no scale along which all values can be arrayed so that for any value or package of values we can say definitively that it has more or less value than some other.

Either of these claims can be made partial. It need not be the case that either all values are reducible or scalable, or none are. A utilitarian may claim that many values reduce to some "stuff," even if not all of them do; an opponent may claim that a few values may reduce to some "stuff," but most of them do not. A utilitarian may claim that many values can be arrayed on a scale, or on a number of scales, even if pockets of incommensurabilities exist; an opponent may claim that some values can be arrayed on a scale or scales, but that there are large or significant areas of incommensurability.

This last debate, about the extent or significance of incommensurability, seems to come down to deeply held conflicting intuitions that have so far proved difficult to capture in theory. Some writers, for example James Griffin, ${ }^{16}$ find that incommensurability is not an important problem. Others, for example Joseph $\mathrm{Raz}_{,}{ }^{17}$ find that it is. Much of their disagreement seems to me related to different intuitions about how to characterize certain kinds of commonplace actions and interactions. In particular, how do we interpret an actor's choices? May we infer commensurability to the extent the actor actually does choose one value over the other? (Should choices between values be read as "trade-offs" in the same way we read commercial exchanges?)

In an example patterned on one of Raz's, suppose that a man is faced with the choice of whether to take a job in a distant city. The job pays $\$ 100,000$ more than his present job, but if he takes it, he will forego the company of his spouse. ${ }^{18}$ If he takes the job, are we entitled to infer that he values the company of his spouse less than he values $\$ 100,000$ ? To make this inference one must be committed to commensurability. The inference assumes the two values can be placed on the same scale, from which we

16. See JAMEs GrifFin, Well-Being: Its MEANING, MEasurement aND Moral IMPORTANCE 75-92 (1986) [hereinafter GRIFFIN, WELL-BEING]; James Griffin, Are There Incommensurable Values?, 7 PHIL. \& PUB. AFF. 39 passim (1977).

17. See Joseph RaZ, THE Morality of FreEdom 321-66 (1986) [hereinafter Raz, MORALITY]; Joseph Raz, Value Incommensurability: Some Preliminaries, 86 PROC. ARISTOTELIAN SOC'Y 117 passim (1985-86) [hereinafter Raz, Value Incommensurability].

18. RAZ, MORALITY, supra note 17, at 345-53. 
can read off that one option is more valuable than the other. Spousal companionship is "traded off" for dollars. Those who make the inference find the language of revealed preference apposite. By making the "trade-off" of his spouse's company in return for $\$ 100,000$, the man "reveals" that the dollar value he places on his spouse's company is less than $\$ 100,000$.

Writers like Griffin think the inference of commensurability is obviously correct ${ }^{19}$-if we see people making choices among things they value, there must be a scale on which those values can be arrayed. But writers like Raz think the inference is an obvious non sequitur ${ }^{20}$-from the fact of choice, nothing about the commensurability of values can be inferred. The nature of an action-its meaning-is simply the conventional understanding of it, and people in our culture do not conceive of these kinds of choices as trades.

I have tried out these conflicting understandings of what such choices mean on law students. Many think choices like this "must" imply commensurability, and an inference about revealed preference seems obviously right; but many think the fact of choice implies nothing at all about commensurability, and that no inference about trade-off is warranted. So far I have not found arguments that change people's minds about this; they seem to be deeply committed either to values being orderly in this way or to their not being so. My own intuitions are with Raz. Someone who says there "must" be a scale "behind" or "underlying" people's choices is like one of Wittgenstein's interlocutors who says there "must" be something common to all games. ${ }^{21}$ There is no "must" about it-unless a socially shared understanding of these choices includes such a "must." The meaning of choices is how they are socially understood. There is no mysterious something that "underlies" such conventions of language and practice.

The fact that people's intuitions are stubbornly diverse about how to interpret actions that could be read as trades carries

19. GRIFFI, WELl-BEING, supra note 16; see also Gerald F. Gaus, Does Compensation Restore Equality?, in COMPENSATORY JUSTICE: NOMOS XXXIII 45, 63-67 (John W. Chapman ed., 1991) (arguing that compensation can result in a return to economic, if not moral, equality).

20. Raz, Value Incommensurability, supra note 17, at 128-34; see also Sunstein, supra note 14 (manuscript at 1 , on file with author).

21. Ludwig Wittgenstein, Philosophical InVestigations 31e-32e (G.E.M. Anscombe trans., 2d ed. 1958). 
through, I think, to a conflicted understanding of compensation. That is, these stubbornly diverse intuitive interpretations are deeply connected with the fact that compensation is a contested concept. To this connection I now turn.

\section{B. Compensation}

How is the debate about value commensurability connected with the issue of compensation? At least at the theoretical level, if we think there are widespread areas of commensurability, we can be more confident that compensation, if calibrated correctly, can amount to rectification. If the fact that we see people making choices between a sum of money and someone's company means that money and company are ranked on a scale, then it should be possible to rank money and having one's limbs intact, money and having one's parent alive, or money and having the companionship of one's child. All we need for rectification in such a case to is to pay the amount of money that is barely enough for the person to have chosen the money over the other thing she values. It may be true that in some cases no amount of money would satisfy this condition. There may be pockets of incommensurability. But those whose intuitions run to inferring that many of our values can be scaled think that such cases are rare.

Both the reductionist and the scalar claims of commensurability can give rise to what I have called commodified conceptions of compensation. In the simplest case, the reductionist claim is put in monetary terms. That is, if it is claimed that there is some "stuff" in terms of which all other values can be expressed, and furthermore that the "stuff" is money, then all values reduce to commodities, and compensation amounts to payment for the sale of one's commodity. The scalar claim also yields a commodified conception of compensation. If each thing someone values can be ranked as either better or worse than a sum of money, then, even if values do not reduce to money, there is in principle a sum of money that will provide rectification. In that case, it still appears that values are commodities that can be sold.

What about reductionism not involving money? Some utilitarians might claim that values are all reducible to one kind of "stuff"-utils, as time-honored convention would have it-but that utils cannot be made equivalent to money, perhaps because utils are wholly subjective. Clearly then, interpersonal utility comparison 
becomes problematic, ${ }^{22}$ and it might seem that this is a less clear case of commodification. Yet as long as utils can be scaled in theory, which seems to be implied in the claim that they are one kind of "stuff," this case is the same as the one involving the scalar assumption by itself.

\section{Corrective Justice}

Many utilitarians have the stubborn intuition I described above to the effect that most values can be scaled. Perhaps that is what makes them utilitarians. Many economists have the same stubborn intuition, with the further unquestioned assumption that all values reduce to money. From this point of view, compensation is unproblematic, at least in theory, even if we believe that in order to satisfy the demands of corrective justice, compensation must amount to rectification. In practice, as I noted earlier, deterrence, rather than corrective justice, often fits better with economic views, so the question of rectification may not often come up for such theorists. Nevertheless, economists often have mixed views as I described, believing that some rights exist other than for consequentialist reasons. In such a view we are likely to find a version of corrective justice, conceived of as restoring wrongly divested entitlements or their equivalents to their rightful holders. Compensation can substitute for the restoration of the entitlement in such a mixed economic view.

Compensation poses a problem for those whose intuitions about commensurability run the other way. If corrective justice requires rectification, and if injury cannot be translated into money, how can payment of money ever amount to rectification, so as to satisfy the demands of corrective justice? The problem, an important one, has been too little noticed, perhaps because the connection between compensation and commensurability has been too little noticed. In my view, the problem will have to be dissolved rather than solved. That is, I think it most likely that the problem incommensurability poses for rectification as corrective justice will only be solved by developing an understanding of corrective justice that does not require rectification.

22. I do not mean to imply that interpersonal utility comparison is not problematic if utils do reduce to money. For one thing, people may obtain extra utils by lying about how much they value something, and this would make comparison difficult. 
In other words, there must be some other way to restore moral balance between the parties than by putting the parties into the status quo ante, which may be irretrievable, or by putting them into a state equivalent in value to the status quo ante, which may be unachievable given the fact of incommensurability. As my earlier description of a core noncommodified conception of compensation reveals, I suggest that compensation can symbolize public respect for rights and public recognition of the transgressor's fault by requiring something important to be given up on one side and received on the other, even if there is no equivalence of value possible. Although I cannot now take on the task of trying to outline an appropriate theory of corrective justice, perhaps such a theory will conclude that this kind of redress is what corrective justice demands. At any rate, it is well to note the importance of incommensurability for the general theory of corrective justice.

\section{Compensation In PRactice: The Pain AND SUFFERING DEBATE}

\section{A. The Traditional View}

In tort law there is a debate in progress about whether compensation should be available for "non-economic" or "nonpecuniary" harms like pain and suffering or intense emotional distress. For these harms, the traditional common law position adheres by and large to a noncommodified conception of compensation.

The Second Restatement of Torts draws a clear distinction between harm to "pecuniary interests" and "bodily harm or emotional distress."23 For pecuniary interests, "compensatory damages are designed to place [the person] in a position substantially

23. RESTATEMENT (SECOND) OF TORTS $§ 903$ (1979). In fact, the line between pecuniary and nonpecuniary harms is fuzzy. For example, loss of a wife's consortium was historically thought of as an economic harm to her husband, because the law focused on the services she owed him; but in a modern understanding, the emotional component of the loss is more important. See, e.g., Diaz v. Eli Lilly \& Co., 302 N.E.2d 555 (Mass. 1973). Moreover, if a goal of economic damages is to make the victim functional again as a worker, it becomes difficult to separate which items are necessary for functioning and which items are instead directed more toward emotional satisfaction; psychotherapy or going back to school to learn something new can be both. In this Essay I ignore the difficulty of drawing the line between pecuniary and nonpecuniary harms, as well as what we can learn from this difficulty, and focus instead on the arguments for and against coinpensation for harms that are determined to be nonpecuniary, however that determination is made. 
equivalent in a pecuniary way to that which he would have occupied had no tort been committed."24 That is, for pecuniary interests compensation is rectification. For other interests, however, compensation means something else. The Restatement goes on to say,

When however, the tort causes bodily harm or emotional distress, the law cannot restore the injured person to his previous position. The sensations caused by harm to the body or by pain or humiliation are not in any way analogous to a pecuniary loss, and a sum of money is not the equivalent of peace of mind. Nevertheless, damages given for pain and humiliation are called compensatory. They give to the injured person some pecuniary return for what he has suffered or is likely to suffer. There is no scale by which the detriment caused by suffering can be measured and hence there can be only a very rough correspondence between the amount awarded as damages and the extent of the suffering. ${ }^{25}$

Thus, the traditional legal position on pain and suffering seems committed to incommensurability. Rectification is not possible ("the law cannot restore the injured person to his previous position," nor to its equivalent), because the value to the victim of freedom from pain and suffering cannot be reduced to money (the harm is "not in any way analogous" to a loss of money, and the desirable state, "peace of mind," is "not the equivalent" of a sum of money), nor can amounts of suffering be arrayed on a scale ("there is no scale") so that they might be paired in parallel with amounts on the money scale.

What then does compensation mean, if it cannot be rectification? About this, the Restatement and the legal discourse it crystallizes supply little, and what they do supply seems to lean ambivalently back toward commensurability. The victim receives "some pecuniary return for what he has suffered;" the dollars awarded in damages do have a "very rough correspondence" to the extent of the harm. If the pecuniary return is "for" the suffering, if indeed it is a "return," the process can be understood in market rhetoric; suffering is an investment in exchange for which a return is received. If there is a "correspondence" between amounts of dollars and amounts of suffering, however "rough," suffering can be un-

24. RESTATEMENT (SECOND) OF TORTS $\S 903 \mathrm{cmt}$. a (1979).

25. Id. 
derstood as scalable in the way that money is, and the earlier denial of commensurability ("there is no scale") is undercut.

I think it is fair to say that the Restatement is accurate in conveying the traditional commitment to incommensurability, both in its ambivalence and in its inarticulateness about what compensation means when it does not mean rectification. Some courts say the purpose of compensation for pain and suffering is to come as close as possible to rectification, even while admitting that there is no way we could know what coming close would mean. The following is typical:

An economic loss can be compensated in kind by an economic gain; but recovery for non-economic losses such as pain and suffering and loss of enjoyment of life rests on "the legal fiction that money damages can compensate for a victim's injury." We accept this fiction, knowing that although money will neither ease the pain nor restore the victim's abilities, this device is as close as the law can come in its effort to right the wrong. We have no hope of evaluating what has been lost, but a monetary award may provide a measure of solace for the condition created. ${ }^{26}$

This passage makes very clear the conflict in the traditional understanding of compensation. We are to come close to something amounting to rectification (aiming to ease the pain and restore the victim's abilities), while at the same time recognizing that we have no hope of evaluating what it is we are to come close to. This conflict may codify the conflicting intuitions about commensurability existing in our legal culture. One possible reason that legal discourse remains ambiguous, then, is that it reflects a conflict between different conceptions of compensation caused by different degrees of commitment to incommensurability. Another possible reason legal discourse has remained ambiguous or inarticulate about what compensation in such cases is for, and has kept making rhetorical gestures like "coming close" to rectification, may be an effort to avoid implying a punitive meaning for compensation. One thing that compensation is not supposed to do in ordinary tort cases is punish the wrongdoer.

If compensation does not make the victim whole and does not punish the wrongdoer, what is left? One suggestion, as the quoted

26. McDougald v. Garber, 536 N.E.2d 372, 374-75 (N.Y. 1989) (citing Skelton v. Collins, 115 C.L.R. 94, 130 (Austl. 1966)). 
passage suggests, is that money can provide solace for the victim. In a well-known article that marks the beginning of the contemporary debate about damages for pain and suffering, Louis Jaffe suggests that "though money is not an equivalent it may be a consolation, a solatium."27 Yet the notion of solace, by itself, does not provide very strong support for a practice of compensation. It does not seem satisfactory from the point of view of corrective justice, since it does not seem to "right the wrong." And it causes problems for justifying any payment at all in cases where the victim is in no condition to find any solace in money because she is dead or permanently comatose.

In fact, when incommensurability is assumed, there is a problem with payment on account of injuries to dead or comatose victims whatever the rationale for damages. In a case where fungible property is wrongfully taken or destroyed, where money damages can presumably make the victim whole, it is easy to understand the victim's rights to compensation not to depend at all on the victim's ability to receive it consciously; and it is easy to understand her compensation rights to pass to her successors just as the equivalent property rights would have. By contrast, if we do not conceive of bodily integrity as a property right-if we do not conceive of it in market rhetoric-it becomes harder to understand why the victim would have any rights to compensation unless she were conscious of suffering, and harder to understand why her compensation rights might inure to her surviving relatives.

Can my right to be free of pain and suffering be transgressed if I am rendered permanently unaware of pain? If not, it appears no damages should be paid to me. Is my right to be free of pain and suffering a "thing" I can will to my children? If not, it appears my surviving children should not be paid damages on account of my suffering. They might, of course, be paid on account of their own emotional distress. ${ }^{28}$ They are in a condition to re-

27. Louis L. Jaffe, Damages for Personal Injury: The Impact of Insurance, 18 LAW \& CONTEMP. PROBS. 219, 224 (1953).

28. The courts traditionally were reluctant to grant recovery for such distress. Sce, e.g., Borer v. American Airlines, Inc., 563 P.2d 858 (Cal. 1977) (holding that children have no nonstatutory cause of action in negligence for loss of parental consortium). But see, e.g., Weitl v. Moes, 311 N.W.2d 259 (Iowa 1981) (holding that a minor has an independent cause of action for loss of the society and companionship of a parent who is tortiously injured by a third party so as to cause a significant disruption or diminution of the parent-child relationship); David J. Leibson, Recovery of Damages for Emotional Distress for Physical Injury to Another, 15 J. FAM. L. 163 (1977) (criticizing judicial re- 
ceive solace; but what sense does it make to pay them money intended to give me solace? Given incommensurability, solace is not a commodity. Solace is not transferable or inheritable like property.

These types of concerns may be reflected in traditional legal requirements that the victim be conscious of suffering, ${ }^{29}$ and, in death cases, that no payment is available for death itself. ${ }^{30}$ These types of concerns also may be reflected in varying legal responses to the issue of payments to survivors on account of the victim's suffering, as well as on account of their own suffering because of the victim's death. ${ }^{31}$ Possibly the traditional limitations on recovery for pain and suffering in these situations reflected recognition of incommensurability.

Given incommensurability between injuries and dollars, another of Jaffe's suggestions about what compensatory damages might mean in the context of pain and suffering seems promising. He suggests that "one who has suffered a violation of his bodily integrity may feel a sense of continuing outrage," and that the payment of money may somewhat "wipe out" this sense of outrage. ${ }^{32}$ Payment of money might succeed in mitigating the sense of outrage because it might make the victim feel that society really values her personality and bodily integrity. "[B]ecause our society sets a high value on money," Jaffe says, it can use "money or price as a means of recognizing the worth of non-economic as well as eco-

luctance to award emotional distress damages in instances of injury to another).

29. See MARILYN MINZER ET AL, DAMAges IN TORT Actions \& 4.21[3] (1989) (citing cases).

30. See RESTATEMENT (SECOND) OF TORTS \& 925 (1979); David W. Leebron, Final Moments: Damages for Pain and Suffering Prior to Death, 64 N.Y.U. L. REV. 256, 260, 278 n.92 (1989).

31. Tort recoveries in cases of the victim's death are governed by statute because at early common law an action did not survive the death of the plaintiff. Survival statutes allow the decedent's survivors to recover any damages the decedent could have recovered, including damages for her own conscious pain and suffering prior to death, but not damages for her own death; wrongful death statutes allow surviving relatives to recover on account of the death itself. See Fitzgerald v. Hale, 78 N.W.2d 509, 514 (Iowa 1956); RESTATEMENT (SECOND) OF TORTS §§ 925-926 (1979). Wrongful death statutes traditionally limited recovery to pecuniary damages associated with the loss, excluding such items as loss of the decedent's companionship, but many states now permit recovery for nonpecuniary loss, especially parents' loss of a child's companionship, and some courts interpret traditional statutes broadly to get a similar result. See, e.g., Green v. Bittner, 424 A.2d 210 (N.J. 1980).

32. Jaffe, supra note 27 , at 224 . 
nomic goods."33 Payment of money "will signify [society's] sincerity."34 This formulation is similar to the conception of redress to which I earlier correlated a core noncommodified conception of compensation. ${ }^{35}$

Jaffe's suggestion resonates with the noncommodified conception of compensation because it attributes a plausible meaning to compensation other than punishment or quid pro quo: recognizing the wrong and signifying its weightiness. Weightiness is signified by using something of great importance in our society-money. It need not be of overwhelming significance that this thing, money, is unrelated to the harm suffered, although exactly what the significance of that unrelatedness is remains to be investigated. The claim is that money may serve as a form of redress, though not rectification, because of its importance in our culture. Moreover, when the wrongdoer is a business entity, as is often the case, money is the only thing important to it, and thus the only significant thing it can yield up. Money is the only thing it can give to a person in recognition of the wrong for which it is responsible.

In spite of his suggested rationale, Jaffe finds the case for damages for pain and suffering to be uneasy. In a consequentialist move that I think is empirically doubtful, he suggests that damages for past pain might not be appropriate because past pain is unlikely to be causing present outrage; presumably, therefore, payment is not needed to relieve outrage. He also is troubled by the very intractability-one might say the very incommensurability! - of incommensurability, which he thinks counts as a reason not to pay anything: "And even granting these arguments there must be set over against them the arbitrary indeterminateness of the evaluation." ${ }^{36} \mathrm{He}$ also thinks that, leaving aside insurance, "do[ing] honor to plaintiff's pain" might be an injustice in light of the "real economic loss" to the negligent defendant; and that, considering insurance, "it is doubtful that the pooled social fund of saving should be charged with sums of indeterminate amount when compensation performs no specific economic function."”37

\footnotetext{
33. Id.

34. Id.

35. See supra Section I(B).

36. Jaffe, supra note 27 , at 224 .

37. Id. at 225 .
} 
We see here the germ of an argument that the mere fact of incommensurability means we should not pay. To Jaffe, the twin earmarks of incommensurability-"indeterminacy" and "no specific economic function"-are enough to render the case for compensation very dubious. By finding the earmarks of incommensurability to be reason enough that no payment should be made, Jaffe's argument denies the significance of incommensurability. Indeed, by treating "honor to plaintiff's pain" as capable of being outweighed by defendant's economic loss, the argument ambivalently reinscribes commensurability. In a sense, Jaffe faithfully tracks the traditional legal position, even as far as encapsulating its ambivalence.

\section{B. Economic Analysis and the Torts "Crisis"}

Some of Jaffe's contemporary successors are pressing these arguments against compensation for pain and suffering ever more forcefully. In order to understand the vehemence of these contemporary arguments, it is necessary to switch to realpolitik. The backdrop of these debates is a "crisis" in tort liability, in which there have been persistent perceptions that juries are awarding "too much" to injured plaintiffs. Insurers and their sympathizers, doctors and their sympathizers, product manufacturers and their sympathizers-all agree that damage awards are too high. Only plaintiffs' attorneys contend otherwise. Compensation for pain and suffering becomes a focal point, because it is claimed that allowing it gives juries too much discretion to implement their sympathies with injured plaintiffs at the expense of (what the defense advocates fear that jurors perceive as) corporate deep pockets.

Incommensurability gives defendants and insurers an argumentative handle. They say that damages for pain and suffering are indeterminate, that there is no way to evaluate their appropriateness, that there is no serious check on the jury's discretion. Many, like Jaffe, have the intuition that the mere fact of indeterminateness is an argument against compensation. Incommensurability is evidently worth big bucks to defendants.

Moreover, there is an ironic way that incommensurability links up the interests of defendants, especially insurers and product manufacturers, with the theoretical view of certain economists. In what has become a standard economic view, put forward in the legal literature by Alan Schwartz, manufacturers of defective 
products should not have to pay those pain and suffering damages that would not have been part of a rational bargain between the manufacturer and the buyer of the product. ${ }^{38}$ That is, unless the product buyer would have bargained and paid for insurance against her own pain and suffering should an accident occur, it is inefficient for tort law to insure her against her loss. I will call this the optimal-insurance view.

The proponents of the optimal-insurance view argue theoretically that it is irrational to insure oneself against future losses of this kind, because of the expected diminished value of one's wealth in an injured state. The optimal-insurance view is part of a larger economic worldview in which it is given that persons are maximizers of dollars or utils, and rationality is maximization. Given the model's assumptions about how much people value their dollars when they are healthy versus how inuch they value them when they are impaired or in pain, a rational calculus shows that it is wealth- or welfare-maximizing not to insure. Thus, it would be irrational to purchase insurance. Proponents of the optimal-insurance view also argue empirically that people's rationality is borne out by their failure to insure. They argue that because we do not see separate insurance markets in which people insure themselves against the risk of future pain and suffering (or loss of quality of life, or loss of consortium, or intense emotional distress), we should infer that people in fact are unwilling to insure themselves against these losses. Because people are unwilling to insure themselves against these losses, the argument proceeds, we should assume that the prices people pay for products do not include payinent for implied warranties against such losses. The contract between consumer and manufacturer should be assumed not to include a bargained-for insurance provision, both because such a provision would be theoretically irrational and because the absence of actual insurance markets for pain and suffering counsels us not to assume such a provision. In the absence of such a bargained-for provision, the argument concludes, no damages should be available for pain and suffering. It would be inefficient for the law to give consumers something they themselves will not pay for. ${ }^{39}$

38. See, e.g., Alan Schwartz, Proposals for Products Liability Reform: A Theoretical Synthesis, 97 YALE L.J. 353, 364-67, 408-11 (1988).

39. See id. at 413-15. 
But what precludes purchase of insurance may be not irrationality but incommensurability. If it is empirically true that consumers do not insure themselves against their own pain and suffering, the best interpretation of their failure to insure may be not that they are maximizing how much they value their money. over different possible states of their health, but rather that they are affirming the incommensurability between pain and suffering and dollars. Perhaps the purchase of pain and suffering insurance would signify to people that their own pain and suffering is a commodity replaceable with money. Perhaps people reject this conception of their own pain and its connection to themselves. It may be that when it comes to their own pain and suffering, people do not conceive of themselves as wealth-maximizers. It may be that they avoid conceiving of their own pain and suffering as commensurable either with money or with other commodities that money might buy. In other words, it may be that people reject the idea of purchasing insurance because they reject the symbolism of the transaction. They may reject the meaning it would have for their selfhood.

The economic worldview of which the optimal-insurance argument is a part is a commodified conceptual scheme. Motivations are conceived of in market rhetoric, rationality is conceived of as maximizing profit or welfare, and justice is conceived of as efficiency. Rationality thus conceived seems to imply an assumption-a model-of widespread commensurability. The economic worldview does not recommend that we determine empirically whether people really do conceive of rationality and justice in market rhetoric, and whether people really do understand values as widely commensurable. As a theoretical model, it is not put forward to track people's conventional understandings. As its adherents make clear, its value as a theoretical model is supposed to lie in its explanatory and predictive force, not in the extent to which it tracks cultural or individual self-understandings about the meaning of transactions. ${ }^{40}$ Proponents of the economic worldview cannot consistently hold that the model's general assumption of

40. That is why economic efficiency can be confidently put forward to explain cultures that have never heard of efficient market exchange. See Edmund W. Kitch, The Intellectual Foundations of "Law and Economics," 33 J. LEGAL EDUC. 184, 187-88, 191 (1983). 
commensurability can be disconfirmed if we discover that in practice people accept incommensurability.

Yet the optimal-insurance view on compensation for pain and suffering seems to want it both ways. The view stops short of supposing that people's valuation of their own bodily integrity or freedom from pain should simply be understood on its general theoretical economic market model; instead, the view tells us that here we look and see what people's conventional understanding is, by observing whether insurance is purchased, and here we attach importance to that conventional understanding. The agreement asks us to attach importance to conventional self-understandings just at the point where incommensurability gets in the way of damage recovery, but no further-not enough to look for widespread incommensurabilty, which, if its significance were similarly treated, could undermine the overall theoretical assumptions of economic analysis.

One way to correct the inconsistency would be forthrightly to assimilate pain and suffering to the market model. That is, in an economic analysis that postulates that all things people value are goods with prices, one could bite the bullet and postulate as well that bodily integrity and freedom from pain are also goods with prices. This is a view I often call universal commodification; we might also call it simple reductionism.

In simple reductionism, bodily integrity is just one more good that people value, and every value is reducible to dollars. Since people are assumed to value their bodily integrity directly in dollars, when injured they can be made whole by paying them the appropriate number of dollars. Thus, simple reductionism leads easily to the core commodified conception of compensation, reflecting the reductionist claim of commensurability. In fact, for simple reductionists the next step would be for the law to admit that pain and suffering is simply another kind of economic loss. ${ }^{41}$

41. See, e.g., Randall R. Bovbjerg et al., Valuing Life and Limb in Tort: Scheduling "Pain and Suffering," 83 Nw. U. L. REv. 908, 913, 927-28 (1989).

[R]ecent empirical research forcefully concludes that intangible harms like the loss of enjoyment of life are economic losses, and proponents apply a disarmingly straightforward calculus to compute the monetary value of such losses....

Evidence on the "value of life" comes from aceumulating findings about how people value risks of injury and death, both on the job and at home .... The most obvious application of this expertise is in lawsuits for wrongful death 
An economic argument about compensation for pain and suffering that is often put forward in opposition to the optimalinsurance view may rely on simple reductionism. The argument claims that consumers are willing to pay to avoid pain and suffering, even if they do not insure against it. In such an economic view, the implicit contract between manufacturer and consumer should be understood to include, at the appropriate price, compensation for such harms, in order to achieve optimal precautions against accidents. I will call this the optimal-precautions view. Thus, Judge Richard Posner opines,

We disagree with those students of tort law who believe that pain and suffering are not real costs and should not be allowable items of damages in a tort suit. No one likes pain and suffering and most people would pay a good deal of money to be free of them. If they were not recoverable in damages, the cost of negligence would be less to the tortfeasors and there would be more negligence, more accidents, more pain and suffering, and hence higher social costs. ${ }^{42}$

The optimal-precautions view is embedded in a deterrence view of torts in general, in which the purpose of paying damages is to deter accidents that would otherwise cost more.

Judge Posner may be a simple reductionist. Although he does not flatly say that injuries reduce to dollars, he does say that pain and suffering are "real costs." In any case, as we can see from his remark, he assumes commensurability between the cost of paying damages (dollars) and those other social costs (pain and suffering) if the dollars are not paid. This is the crux of the optimal-precautions view; it must assume that we can tell which costs are "higher." Thus, although the optimal-precautions view need not explicitly reduce injuries to dollars, it is committed to the possibility of ranking injuries on a scale with dollars so that we can determine at what point the dollars are equal to or greater than the value of not being injured. ${ }^{43}$ This view reflects at least the scalar

and survival actions, but it would also be relevant to pain and suffering, loss of pleasure of life, and other new notions of intangible loss in personal injury cases. These losses would be newly supportable as "econoinic" elements of loss, and would have corresponding and specific dollar values, not inerely vague verId. bal descriptions.

42. Kwasny v. United States, 823 F.2d 194, 197 (7th Cir. 1987).

43. Presumably this value would be ineasured by observing what people are willing 
claim of commensurability, if not the reductionist claim. It arrives at the conclusion that damages for pain and suffering ought to be paid, but does so by committing itself to a commodified conception of compensation.

\section{A Reform Proposal}

Another way to deal with the apparent inconsistency in the economic optimal-insurance argument is to investigate in a much broader way what our actual understandings of compensation are. What would such an investigation reveal? We could take our understanding to be the somewhat ambiguous traditional conception, reflected in the passage from the Restatement quoted above, that compensation for pain and suffering provides redress in some way other than by making freedom from injury commensurable with money. We could recognize that corrective justice is at least an important basis for tort law, and try to develop a view of corrective justice that does not require the rectification that incommensurability precludes.

We could also take it to be the case, as I suggest, that there is no one understanding of compensation that is "ours." The Restatement's ambivalence may faithfully mirror conflict. Intuitions are divided about commensurability, and so are intuitions about what compensation means. Our practice of compensation is conflicted; commodified and noncommodified understandings coexist. What should we make of the conflict, practically speaking?

One suggestion for alleviating the "crisis" in tort liability seems to advise us to ignore it. We should bypass conflicting theories of tort and compensation prevalent in legal rhetoric and look more systematically at the bottom line in practice. How much money is being paid for what? Two recurrent complaints about awards for pain and suffering are that they are indeterminate, causing perceptions of unfairness and causing deterrence theory not to work, and that they leave it open to juries to give plaintiffs the moon. The suggestion is that both worries can be alleviated by compiling extensive data on awards in specific categories of cases and requiring future awards presumptively to adhere to a schedule

to pay to avoid being injured. See W. KIP VIscusI, Fatal Tradeorrs: PUblic aNd PRIVATE RESPONSIBILITIES FOR RISK (1992). 
based on this data. ${ }^{44}$ Outliers will be prevented, or at least juries will have to justify them.

I am sympathetic with the pragmatic methodology that would counsel us to work around our conflicts by closer attention to concrete practice, rather than attempt to resolve them a priori in theory. At first glance, therefore, the suggestion that the tort "crisis" can be alleviated by legislating schedules based upon past awards seems promising. ${ }^{45}$ Yet $I$ think it is especially important for a pragmatic approach to try to find out how much incommensurability actually exists and whether we need it for anything important. I believe it is important not to beg the question whether people have significant commitments to incommensurability, and if so, whether such commitments are important to human flourishing.

It seems to me that the suggestion that we legislate schedules based upon past awards does risk begging this question by assuming a species of commensurability. I think this tendency to assume commensurability can be seen in the way these reformers approach the issue of how the law should delineate the specific categories in which damage awards should be made comparable. One suggestion is that severity of injury and age of the injured party are the main relevant factors, with the implication that severity of injury is something that can at least be roughly scaled or placed in categories ranging from least to most severe. ${ }^{46}$ By linking such a scale to ranges of dollar amounts, this approach asks the law to institutionalize a scalar version of commensurability, though not one that is outright reductionist in equating freedom from injury with dollars.

One group of researchers finds a scale of severity used by insurers to evaluate malpractice cases to be useful. I reproduce it in a footnote to show both the intuitive appeal of such a scale, that we do conventionally recognize that some injuries are worse

44. See James F. Blumstein et al., Beyond Tort Reform: Developing Better Tools for Assessing Damages for Personal Injury, 8 YALE J. ON REG. 171 (1991); Bovbjerg et al., supra note 41; Frederick S. Levin, Pain and Suffering Guidelines: $A$ Cure for Damages Measurement "Anomie," 22 U. MICH. J.L. REF. 303 (1989).

45. Of course, it is necessary to face the serious problem of determining the circumstances under which it would be just simply to force future awards to follow the patterns of the past. For example, in the past, pain and suffering from medical malpractice has seeined to be "worth" more than pain and suffering from auto accidents. Should this pattern be made into a rule, or does it instead require correction? See Bovbjerg et al., supra note 41 , at 943 n.166.

46. Id. at $938-42$. 
than others, and how problematic are attempts to formalize that intuition. ${ }^{47}$ Another researcher simply lists eighteen types of injury $^{48}$ and sets out data showing how the legal system has coinpensated for them. According to his research, cancer and burn victims are most likely to receive some award for pain and suffering, and people who suffer paraplegia, quadriplegia, or brain damage are likely to receive the largest pain and suffering awards. ${ }^{49}$ Assuming this research is valid, what should we do with it? The researchers advocate, in essence, that the law should adopt a species of commensurability by enacting a schedule that makes these trends into legal rules.

\begin{tabular}{|c|c|}
\hline Severity of Injury Scale & Examples \\
\hline 1. Emotional only & Fright, no physical damage. \\
\hline 2. Temporary insignificant & $\begin{array}{l}\text { Lacerations, contusions, minor scars, rash. } \\
\text { No delay. }\end{array}$ \\
\hline 3. Temporary minor & $\begin{array}{l}\text { Infections, misset fracture, fall in hospital. } \\
\text { Recovery delayed. }\end{array}$ \\
\hline 4. Temporary major & $\begin{array}{l}\text { Burns, surgical material left, drug side-effect, } \\
\text { brain damage. Recovery delayed. }\end{array}$ \\
\hline 5. Permanent minor & $\begin{array}{l}\text { Loss of fingers, loss or damage to organs. } \\
\text { Include non-disabling injuries. }\end{array}$ \\
\hline 6. Permanent significant & $\begin{array}{l}\text { Deafness, loss of limb, loss of eye, loss of } \\
\text { one kidney or lung. }\end{array}$ \\
\hline 7. Permanent major & $\begin{array}{l}\text { Paraplegia, blindness, loss of two limbs, } \\
\text { brain damage. }\end{array}$ \\
\hline 8. Permanent grave & $\begin{array}{l}\text { Quadraplegia, severe brain damage, lifelong } \\
\text { care or fatal prognosis. }\end{array}$ \\
\hline
\end{tabular}

National Assoctation of Insurance Commissioners, Malpractice Clalms: Final COMPILATION 10 (M. Patricia Sowka ed., 1980). Bovbjerg, Sloan, and Blumstein think this scale would be useful in preparing an appropriate damages schedule, and they claim that severity of injury, measured by this scale, accounts for two-fifths of the variance in reported damage awards. Bovbjerg et al., supra note 41 , at 923 . They find the categories "intuitively appealing," with the possible exception of the "emotional only" category, which encompasses too wide a range. For example, surely there are emotional injuries that are worse than lacerations and contusions. Id. at 920. Others might find the death category just as debatable; some things are worse than death.

Even if the scale strikes us as intuitively capturing a rough sense of increasing severity of injury, why should we assume that pain and suffering vary linearly with the severity of the injury? On the contrary, death, and possibly "severe bram damage," brings an end to suffering.

48. See W. Kip Viscusi, Pain and Suffering in Product Liability Cases: Systematic Compensation or Capricious Awards? 8 INT'L REV. L. \& ECON. 203, 207 (1988) (listing amputation, asphyxiation, brain damage, bruise, burn, cancer, concussion, dermatitis, dislocation, disease-other, electrical shock, fracture, laceration, para/quadriplegia, poison, respiratory, sprain/strain, and other).

49. Id. at $207-08$. 
Whether we should declare a species of commensurability in this way is unclear. If we think incommensurability is an important commitment in self-constitution and in life as we know it, then before enacting such legal rules we at least would like to know whether the law itself has any effect on the existence of incommensurability. How deep and how extensive are people's commitments to incommensurability? If the law does declare commensurability, will it cause people's commitment to incommensurability to fade?

This question is very important, both theoretically and practically, but I must say that, right now, I do not know how to approach trying to answer it. I offer tentative thoughts below, inviting others to tackle the problem.

\section{COMPENSATION PRACTICE AND THE CUlture-SHAPING FUNCTION OF LAW}

Can legal rules in fact bring about commensurability? Is the existence of incommensurability something that can vary depending upon the state of the legal system? The answer is yes, if (1) incommensurability is part of the conventional cultural system of meaning (our form of life), and if (2) the state of the legal system affects that system of meaning. With respect to (1), I am inclined to agree with Joseph $\mathrm{Raz}$ that incommensurability is an artifact of our shared discourse. (What else could it be?) With respect to (2), I am also inclined to think that the law matters for that shared discourse. But the details of how it matters are not easy to specify.

In a view that I find attractive, law not only reflects culture, but also shapes it. The law is a powerful conceptual-rhetorical, discursive-force. It expresses conventional understandings of val$\mathrm{ue}$, and at the same time influences conventional understandings of value. Yet mere recognition of this two-way street is too general to be useful. It is not easy to say when we should view the law as predominantly reflecting background culture and when we should view the law as a moving force in changing that culture. Nevertheless, it seems in general that, at least sometimes, the law can be a cultural moving force. If this is a useful way to see the function of law, and I think it is, then the law may indeed influence how we understand ourselves and our values, and, in particular, whether we understand certain aspects of ourselves, such as bodily integrity and freedom from pain, to be incommensurable with money. 
I have said that our conventional understanding of what compensation means is conflicted, that compensation is a contested concept. Suppose, however, that someone believes that because we inhabit a market society, the main meaning of paying money for injuries is that money and injuries are exchangeable commodities. The observer might believe that our compensation practice directly reflects a commodifled conception of compensation; we really are saying that injuries are reducible to dollars or can be placed on a scale with dollars. Or, more subtly, the observer might believe that even if our compensation practice is primarily meant, as traditional legal discourse would have it, not to equate injuries and dollars, but rather to provide a different sort of redress, nevertheless, since the practice is located in a market society, the practice will come to be interpreted as commodification and indeed will create commodification. That is, when we live in a world in which many or most things people need and want are routinely traded as commodities, and when we see dollars systematically being paid to people after they are injured, and in some way "for" or "on account of" the injury, we are likely to come to conceive of freedom from injury as another commodity bearing exchange value, even if we do not now conceive of it that way. If such an observer holds that conceiving of bodily integrity and freedom from pain as commodities leads to a degradation of personhood and an inferior conception of human flourishing, then he may argue that compensation for pain and suffering should be abolished.

This is one way to read the arguments of Richard Abel, ${ }^{50}$ who advocates a social insurance scheme. He would replace the tort system with one that grants money to people regardless of whether their misfortunes are caused by their own fault, other people's fault, an unavoidable accident, an illness, or a congenital disability. Abel's ideal system would not compensate for pain and suffering; such damages "commodify our unique experience." Nor would it compensate for loss of consortium or witnessing injury to a loved one; such damages "commodif[y] love." 52 In saying that damages operate to "commodify," Abel implies either

50. See, e.g., Richard Abel, A Critique of Torts, 37 UCLA L. REv. 785, 804-06 (1990) Politics makes strange bedfellows. Revolutionary anticommodifiers may lie down with the economic allies of corporate defendants. See id. at 831.

51. Id. at 804 .

52. Id. at 805 . 
that our shared understanding of compensation is a commodified conception, or that the practice of payment, in our market social context, can make it so.

Another observer of our discursive practice of compensation might not be so ready to think that the commodified conception prevails, or will come to prevail. ${ }^{53}$ Perhaps, even though market rhetoric is an important conceptual scheme in our culture, and even though we are influenced in our conceptualization of compensation by a legal system that pays people dollars in a context that expresses that the payment is "for" the injury, we can still maintain a noncommodified conception of compensation. Perhaps the noncommodified conception is robust; perhaps incommensurability is robust.

I can restate the issue this way. If we do conceive of compensation in primarily a noncommodified way-if we are clear that it is not a quid pro quo, but rather a symbolic action that reinforces our commitments about rights and wrongs-then the practice of paying compensation does not signify that we conceive of the harms to persons for which we pay it as commodities. Yet one who values noncommodified understandings of human attributes, quality of life, and bodily integrity might still fear that the noncommodified conception of compensation is in danger of giving way sooner or later to the commodified conception, under the onslaught of constant payment "for" injuries in the context of a culture that readily understands analogous interactions as market exchanges, perhaps helped along by the rhetoric of economic analysis. How should we evaluate this fear? How robust is the noncommodified conception?

One thing we can do is look and see how prevalent the noncommodified conception is in legal discourse, and try to evaluate whether it is becoming weaker or more questionable. The investigation could pursue a "thick description" of arguments in tort cases, jury instructions, and trial and appellate court opinions. My supposition is that this investigation would show that the traditional noncommodified conception, albeit ambiguous and conflict-

53. If the observer is a proponent of a comprehensive social insurance scheme, she still might hold that no payments should be made on account of pain and suffering, not primarily because the payments express or foster commodification, but rather because such payments will need to be foregone if there is to be enough money to go around to satisfy everyone's basic needs. See, e.g., SuGARMAN, supra note 5, at 36-38. 
ed, is holding firm. Or the investigation could pursue an analysis of the rhetoric of tort scholarship. My supposition is that this investigation would show that the commodified conception is gaining ground.

We also could try to evaluate just how deeply entrenched our intuitions of incommensurability are, for those of us who have them, though I do not know how such an investigation would proceed. Perhaps understandings involving incommensurability are so deeply entrenched that no amount of market rhetoric can dislodge them or the conceptions of human values they underwrite. If this is how things are, then commodified and noncommodified conceptions will simply continue to coexist as they do now, and they will pretty well track people's commitments about incommensurability. People who accept incommensurability will tend to have a noncommodified conception of compensation, and people who do not accept incommensurability will tend to have a commodified conception of compensation. On the other hand, perhaps our intuitions of incommensurability will turn out to be more fragile-perhaps the conventional discursive system that underwrites them will turn out to be more malleable-in which case incommensurability may tend to disappear under the continued infiuence of surrounding market discourse and practice.

\section{CONCLUSION}

At least in the context of damages for personal injury, compensation is a contested concept. Noncommodified conceptions are committed to incommensurability. Commodified conceptions are committed to commensurability. These conflicting conceptions coexist within our legal practice and discourse. Once we recognize the conflict, we can gain better insight into the debate about compensation for pain and suffering. We can also understand the importance of incommensurability for thinking about corrective justice in general. For now, though, it remains unclear how we should evaluate the effect of the law's own symbolic force in maintaining the existence of incommensurability. 